\title{
Finding Promiscuous Old Drugs for New Uses
}

\section{Sean Ekins ${ }^{1,2,3,4}$ and Antony J. Williams ${ }^{5}$}

${ }^{1}$ Collaborations in Chemistry, Fuquay Varina, NC.

${ }^{2}$ Collaborative Drug Discovery, Burlingame, CA.

${ }^{3}$ Department of Pharmacology, University of Medicine \& Dentistry of New Jersey-Robert Wood Johnson Medical School, Piscataway, NJ.

${ }^{4}$ School of Pharmacy, Department of Pharmaceutical Sciences, University of Maryland, Baltimore, MD.

${ }^{5}$ Royal Society of Chemistry, Wake Forest, NC 


\section{Why old drugs 8}

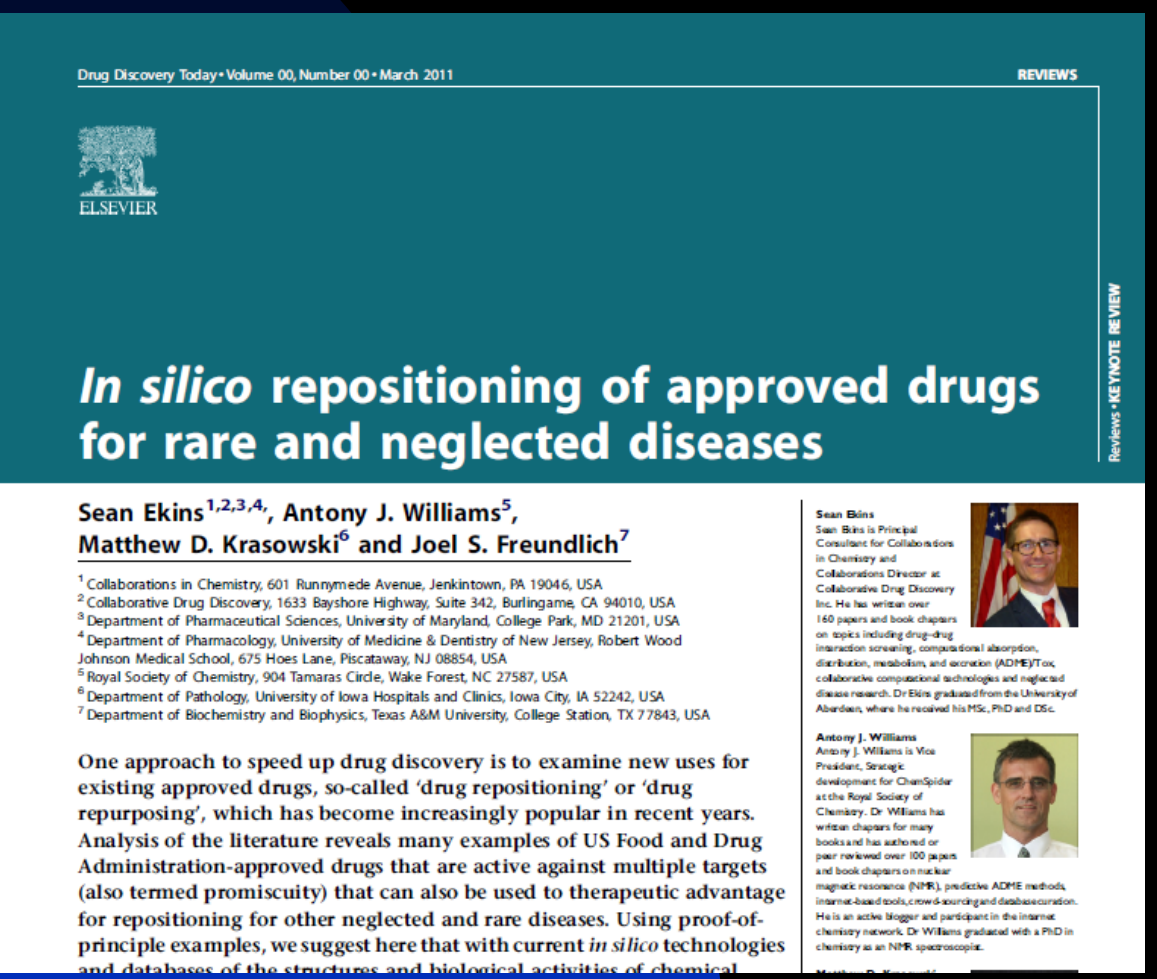

More cost effective R\&D?

Repurposing/ repositioning -Quicker to bring to market?

Recent focus on neglected \& rare diseases

Over 7000 diseases affecting less than 200,000 1000 's of diseases with no treatments

$>300$ orphan drugs approved since 1983

Ekins S, Williams AJ, Krasowski MD and Freundlich JS, Drug Disc Today, 16: 298-310, 2011 


\section{Just some of the many rare disease groups}

Abigail Alliance for Better Access to Developmental Drugs

Addi \& Cassi Fund

American Behcet's Disease Association

Amschwand Sarcoma Cancer Foundation

BDSRA (Batten Disease Support and Research Association)

Beyond Batten Disease Foundation

Blake's Purpose Foundation

Breakthrough Cancer Coalition

Canadian PKU \& Allied Disorders

Center for Orphan Disease Research and Therapy, University of

Pennsylvania

Children's Cardiomyopathy Foundation

Cooley's Anemia Foundation

Dani's Foundation

Drew's Hope Research Foundation

EveryLife Foundation for Rare Diseases

GIST Cancer Awareness Foundation

Hannah's Hope Fund

Hope4Bridget Foundation

Hypertrophic Cardiomyopathy Association - HCMA

I Have IIH

ISRMD (International Society for Mannosidosis and Related Diseases)

Jacob's Cure

Jain Foundation

Jonah's Just Begun-Foundation to Cure Sanfilippo Inc.

Kids V Cancer

Kurt+Peter Foundation

LGMD2I Research Fund

Lymphangiomatosis \& Gorham's Disease Alliance

MAGIC Foundation

Manton Center for Orphan Disease Research

MarbleRoad

Mary Payton's Miracle Foundation

Midwest Asian Health Association (MAHA)
MPD Support

National Gaucher Foundation

National MPS Society

National Organization Against Rare Cancers

National PKU Alliance

National Tay-Sachs \& Allied Diseases Association

New Hope Research Foundation

NextGEN Policy

Noah's Hope - Batten disease research fund

Our Promise to Nicholas Foundation

Oxalosis and Hyperoxaluria Foundation

Partnership for Cures

Periodic Paralysis Association

RARE Project

Ryan Foundation for MPS Children

Sanfilippo Foundation for Children

Sarcoma Foundation of America

Solving Kids' Cancer

Taylor's Tale: Fighting Batten Disease

Team Sanfilippo Foundation

The Alliance Against Alveolar Soft Part Sarcoma

The Life Raft Group

The NOMID Alliance

The Transverse Myelitis Association

The XLH Network, Inc.

United Pompe Foundation

\section{Many of these groups are doing R\&D on a shoestring how can we help?}




\section{One erample of why Pharmaecutieal RED needs disupting}

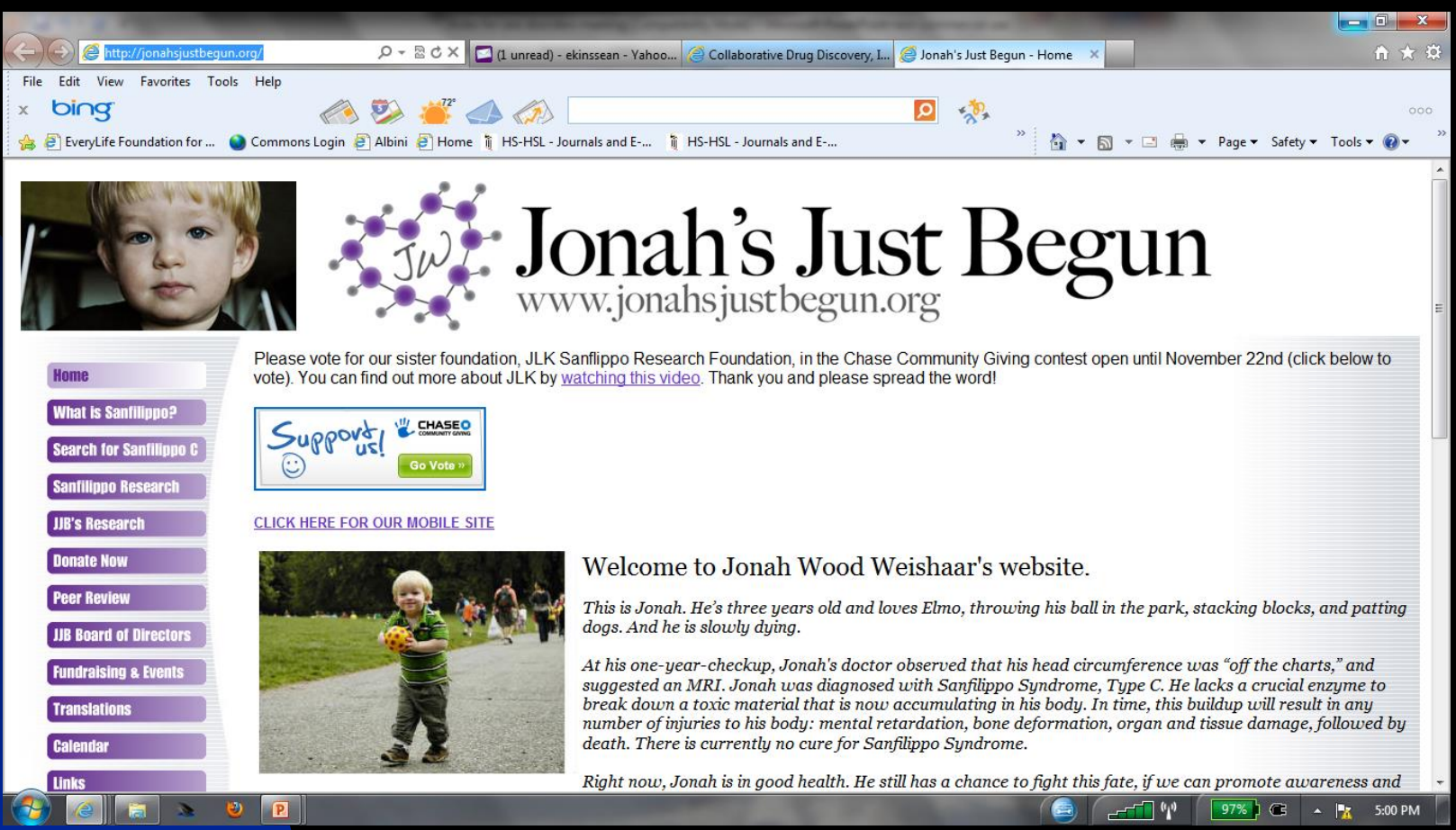

Jonah has Sanfilippo Syndrome - Mucopolysaccharidosis type III - cannot degrade heparan sulfate - Neurodegeneration

Jonah's mum, Jill Wood started a foundation, raises money, awareness, funds ground breaking research happening globally. Willing to sell her house to fund research to save Jonah.

She is in a race against time - what can we do to translate ideas from bench to patient faster?

How do we get more ideas tested, can we focus on approved drugs?

How can we help parents and families? 


\section{Arailabiliky of libraries of fPA drugs}

\section{PRODUCT DATA SHEET}

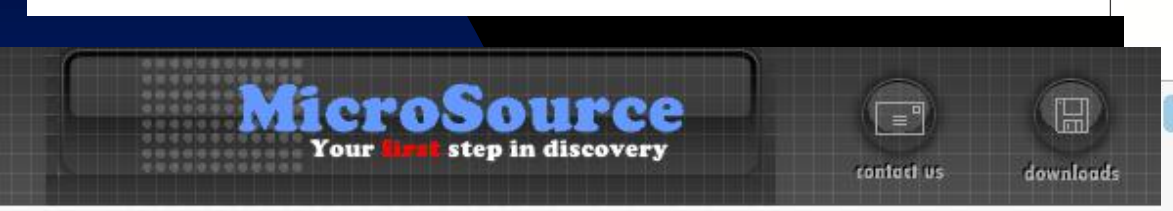

\section{Enzo}

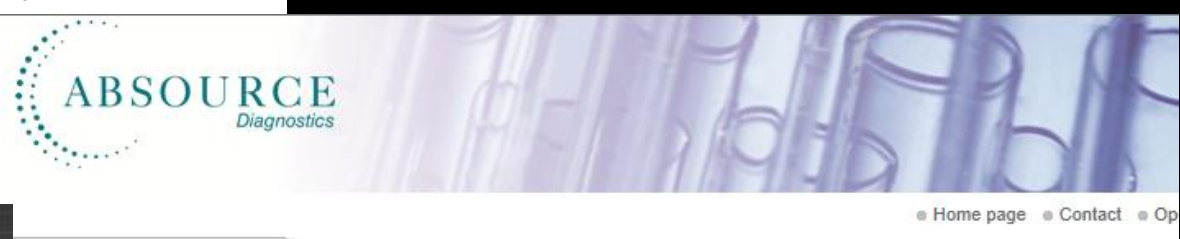

Order
Phone: +4989461485012

Fax: +4989461485022

E-mail: order@absource.net

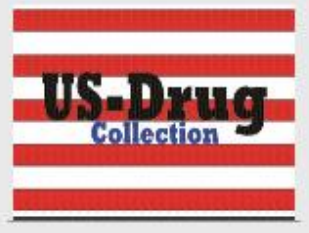

us Drug Collection

An important collection of 1040 drugs that have reached clinical trial stages in th has been assigned USAN or USP status and is included in the USP Dictionary (U.) 2005), the authorized list of established names for drugs in the USA.
Prestwick Chemical Library ${ }^{\circledR}$

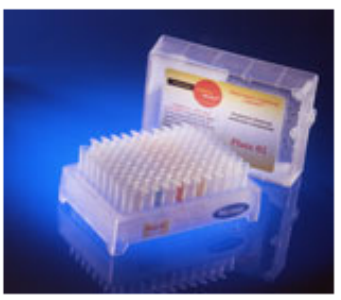

The Prestwick Chemical Library ${ }^{\oplus}$ contains 1200 small molecules, $100 \%$ FDA approved drugs, thus it presents the greatest possible degree of « drug-likeliness $»$. The active compounds were selected for their high chemical and pharmacological diversity as well as for their known bioavailability and safety in humans. The Prestwick Chemical Library (2) was designed to reduce the risk of "low quality" hits, reduce the cost of the initial screening, and accelerate lead discovery.

What's the ideal use of the library?

The strategy we recommend is the "SOSA Approach" (C.G. Wermuth, J. Med. Chem. 2004, 47, 1303-1314). It consists of submitting to the target only a limited number of highly diverse drug molecules for which bioavailability and toxicity studies have already been performed and which have proven usefulness in humans. This initial screening will provide hits that will then be used as starting points for a drug optimization program which will rely on medicinal chemistry expertise. It can be noticed that, if the initial hit has sufficient affinity for the target, it could be immediately tested in patients.

Johns Hopkins Clinical Compound library- made compounds available at cost 


\section{finding Promiseuous Old Drugs for new Ures}

In late 2010..searched the literature

Many groups in vitro HTS

Libraries of FDA approved drugs against various whole cell or target assays

Research published in the prior six years - 34 studies -.

1 or more compounds with a suggested new bioactivity

13 drugs were active against more than one additional disease in vitro

Perhaps screen these first? 


\section{Finding Promiseuous Old Prugs for hew Uses}
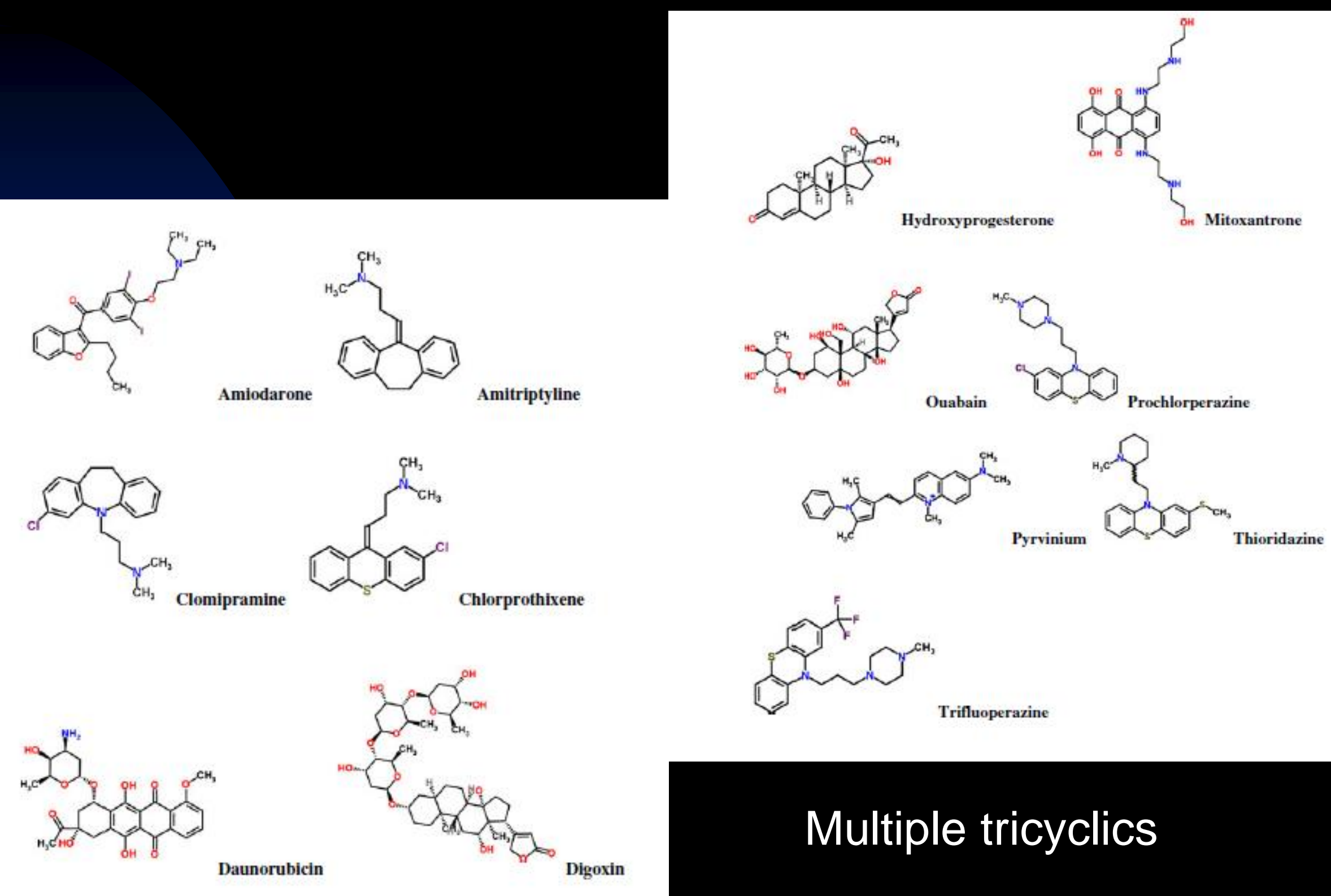

Ekins and Williams, Pharm Res 28(8):1785-91, 2011

\section{Multiple tricyclics}

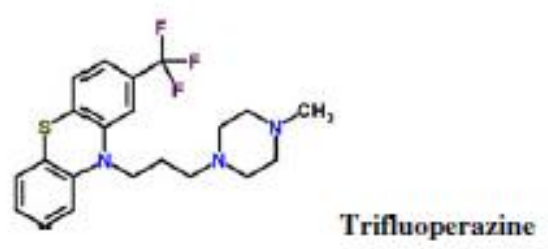




\section{finding Promisevous Old Prugs for hew Ures}

Amitriptyline and clomipramine $=$ suppress glial fibrially acidic protein Cho et al., Human Mol Genet (2010) 19: 3169-78

Amitriptyline and clomipramine $=$ mitochondrial permeability transition Stavrovskaya et al., J Exp Med (2004) 200: 211-22

Pyrvinium Pamoate (antihelmintic) $=$ anti Tuberculosis

Lougheed et al., Tuberculosis (2009) 89: 364-70

Pyrvinium Pamoate (antihelmintic) $=$ anti Antiprotozoal C. parvum Downey et al., Antimicrob Agents Chemother (2008) 52: 3106-12

Pyrvinium Pamoate (antihelmintic) $=$ anti Antiprotozoal T. Brucei Mackey et al., Chem Biol Drug Des (2006) 355-63 


\section{Analysis of datasets}

\begin{tabular}{|c|c|c|c|c|c|c|c|c|}
\hline Dataset & ALogP & $\begin{array}{l}\text { Molecular } \\
\text { Weight }\end{array}$ & $\begin{array}{l}\text { Number } \\
\text { of } \\
\text { Rotatable } \\
\text { Bonds }\end{array}$ & $\begin{array}{l}\text { Number } \\
\text { of Rings }\end{array}$ & $\begin{array}{l}\text { Number } \\
\text { of } \\
\text { Aromati } \\
\text { c Rings }\end{array}$ & $\begin{array}{l}\text { Number of } \\
\text { Hydrogen } \\
\text { bond } \\
\text { Acceptors }\end{array}$ & $\begin{array}{l}\text { Number } \\
\text { of } \\
\text { Hydrogen } \\
\text { bond } \\
\text { Donors }\end{array}$ & $\begin{array}{l}\text { Molecular } \\
\text { Polar } \\
\text { Surface Area }\end{array}$ \\
\hline $\begin{array}{c}\text { Compounds } \\
\text { identified in vitro with } \\
\text { new activities ( } N= \\
109)^{*}\end{array}$ & $\begin{array}{c}3.1 \pm \\
2.6\end{array}$ & $428.4 \pm 202.8$ & $5.4 \pm 3.8$ & $3.8 \pm 1.9$ & $2.0 \pm 1.4$ & $5.6 \pm 4.2$ & $2.0 \pm 1.9$ & $89.6 \pm 69.3$ \\
\hline $\begin{array}{l}\text { Compounds } \\
\text { identified in vitro with } \\
\text { multiple new } \\
\text { activities }(N=13)\end{array}$ & $\begin{array}{c}3.6 \pm \\
2.7\end{array}$ & $442.8 \pm 150.0$ & $5.1 \pm 3.1$ & $4.2 \pm 1.5$ & $1.8 \pm 1.2$ & $5.5 \pm 4.6$ & $2.2 \pm 3.3$ & $79.5 \pm 78.8$ \\
\hline
\end{tabular}

Ekins and Williams, Pharm Res 28(8):1785-91, 2011 


\section{finding Promireuous Old Prugs for new Uses}

109 molecules were identified by screening in vitro

Promiscuous compounds do not appear different to whole dataset

Molecules are close to natural product lead like $(\mathrm{MW}<460, \log \mathrm{P}<4.2)$

Rosen et al., J Med Chem (2009) 52: 1953-62

1193 Oral drugs mean MW 343.7 CLOGP 2.3

Vieth et al., J Med Chem (2004) 47: 224-32

Others have shown GPCR promiscuous cpds vs selective have higher MW and clogP

Azzaoui et al., ChemMedComm (2007) 2: 874-80

Our promiscuous cpds had carbon skeletons identified as promiscuous 


\section{fPA Rars Pirsars Rersareh Patabars}

- The FDA resource, the rare disease research database (RDRD),

(http://www.fda.gov/ForIndustry/DevelopingProductsforRareDiseasesConditions/Howt oapplyforOrphanProductDesignation/ucm216147.htm)

- Lists Orphan-designated products with at least one marketing approval for a common disease indication, for a rare disease indication, or for both common and rare disease indications.

- In the last category there are less than 50 molecules (including large biopharmaceutical drugs).

- These tables do not capture the high throughput screening (HTS) data generated to date

•FDA databases for rare disease research are XL files!! 
We have curated the data and uploaded in

NEW $\square$ Joel Malaria

Show/hide projects CDD with the help of Antony Williams at the Royal Society of Chemistry

Public Data

$\square$ ChemBridge KII all nd

$\square$ ChemBridge KINASet

$\square$ ChemBridge NOVACo

$\square$ Chemik 2010 Catalog

NEW NEW $\checkmark$ FDA Drugs Repurposed using HTS methods

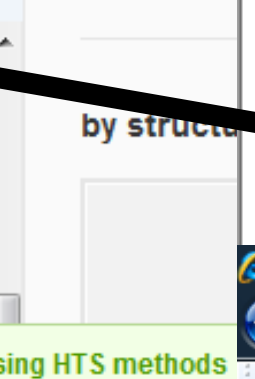

\section{$\square$ Novartis GNF-Pf Datas}

Launch trie structure Ealtor

$\checkmark$ Orphan-designated pr

NEW $\checkmark$ Orphan-designated products with at least one marketing approval for a rare disease indication C Search - Collaborative Drug Discovery - Windows Internet Explorer provided by Yahoo!

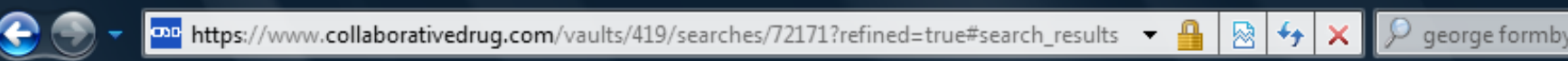
File Edit View Favorites Tools Help

$\square$ FDANOrphan Drugs

$\square$ IUPUI - Distributed Dru by molecu

$\square$ JHU JHCCL Plasmod

$\square$ LIPID MAPS Structure

$\square$ Malaria/Trypanosome

$\square$ Malaria: Drexel Public

$\square$ Malaria: Johns Hopkin

$\square$ Malaria: Natural Produ

Favorites

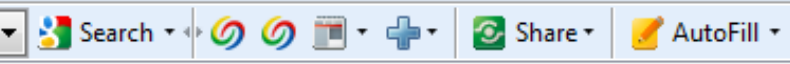

- D \#recommendSource=radi... $\mathrm{D}$ Search - Collaborative ... $\times$ \& In silico repositioning of a...

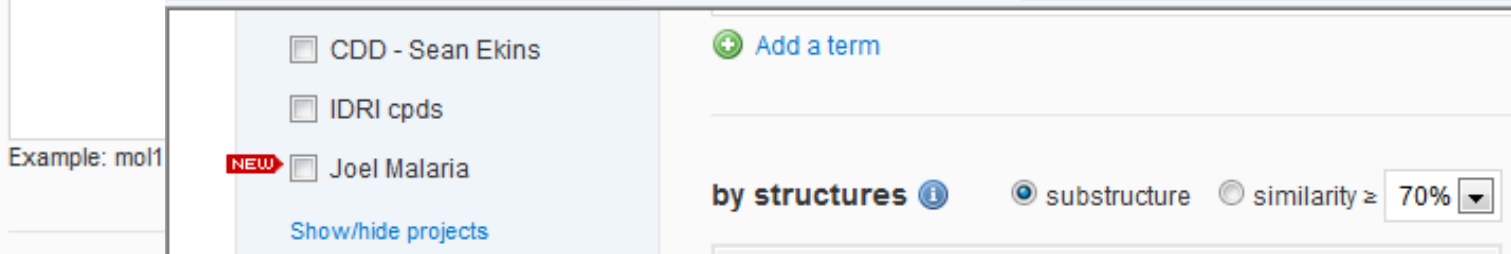

Save this U. 2 Windows Expl... 질 DDT table 1I

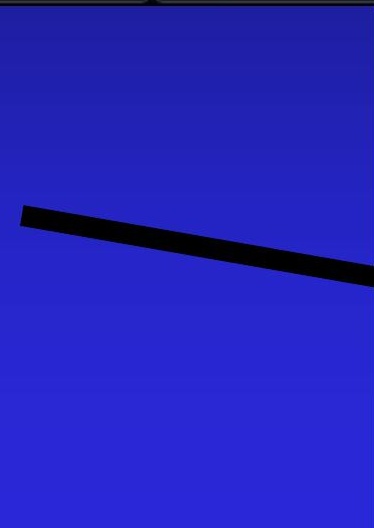

Public Data

$\square$ ivaland. rmenamumente

$\square$ Malaria: PlasmoDB

$\square$ Malaria: U.S. Army Sur

$\square$ MLSMR

$\square$ Novartis GNF-Pf Datas

$\checkmark$ Orphan-designated products with at least one marketing approval for a common disease indication hide NEw $\square$ Orphan-designated pr
$\square$ PDSP Ki Database
$\square$ sacchettini et al review

\section{by molecule keywords (1)}

$$
\text { any field }
$$

$\nabla$

\section{Example: mol1 OR synonym2 AND NOT userfield3}

by chemical pro Molecular weigh

$$
\log \mathrm{F}
$$

$\mathrm{H}$-bond donors $\mathrm{H}$-bond acceptors Lipinski violations Heavy atom coun Polar surface area Rotatable bonds 


\section{Analygir of datarets}

\begin{tabular}{|c|c|c|c|c|c|c|c|c|}
\hline Dataset & ALogP & $\begin{array}{l}\text { Molecular } \\
\text { Weight }\end{array}$ & $\begin{array}{l}\text { Number } \\
\text { of } \\
\text { Rotatable } \\
\text { Bonds }\end{array}$ & $\begin{array}{l}\text { Number } \\
\text { of Rings }\end{array}$ & $\begin{array}{c}\text { Number } \\
\text { of } \\
\text { Aromati } \\
\text { c Rings }\end{array}$ & $\begin{array}{c}\text { Number of } \\
\text { Hydrogen } \\
\text { bond } \\
\text { Acceptors }\end{array}$ & $\begin{array}{l}\text { Number } \\
\text { of } \\
\text { Hydrogen } \\
\text { bond } \\
\text { Donors }\end{array}$ & $\begin{array}{l}\text { Molecular } \\
\text { Polar } \\
\text { Surface Area }\end{array}$ \\
\hline $\begin{array}{l}\text { Orphan designated } \\
\text { products with at } \\
\text { least one marketing } \\
\text { approval for a } \\
\text { common disease } \\
\text { indication }(\mathrm{N}=79)\end{array}$ & $\begin{array}{l}1.4 \pm \\
3.0^{b}\end{array}$ & $\begin{array}{c}353.2 \pm 218.8 \\
a\end{array}$ & $5.3 \pm 6.4$ & $\begin{array}{c}2.8 \pm 1.7 \\
a\end{array}$ & $\begin{array}{c}1.2 \pm 1.3 \\
b\end{array}$ & $5.3 \pm 6.0$ & $2.5 \pm 3.0$ & $99.2 \pm 110.7$ \\
\hline $\begin{array}{l}\text { Orphan designated } \\
\text { products with at } \\
\text { least one marketing } \\
\text { approval for a rare } \\
\text { disease indication ( } \mathrm{N} \\
=52)^{\#}\end{array}$ & $\begin{array}{l}0.9 \pm \\
3.3^{b}\end{array}$ & $\begin{array}{c}344.4 \pm 233.5 \\
a\end{array}$ & $5.3 \pm 5.3$ & $\begin{array}{c}2.4 \pm 1.9 \\
b\end{array}$ & $\begin{array}{c}1.3 \pm 1.4 \\
\mathrm{a}\end{array}$ & $6.2 \pm 4.2$ & $2.7 \pm 2.8$ & $114.2 \pm 85.3$ \\
\hline
\end{tabular}

orphan repurposed hits are less hydrophobic smaller MW than in vitro screening cpds

Molecules close to lead-like and closer to oral drugs

Ekins and Williams, Pharm Res 28(8):1785-91, 2011 


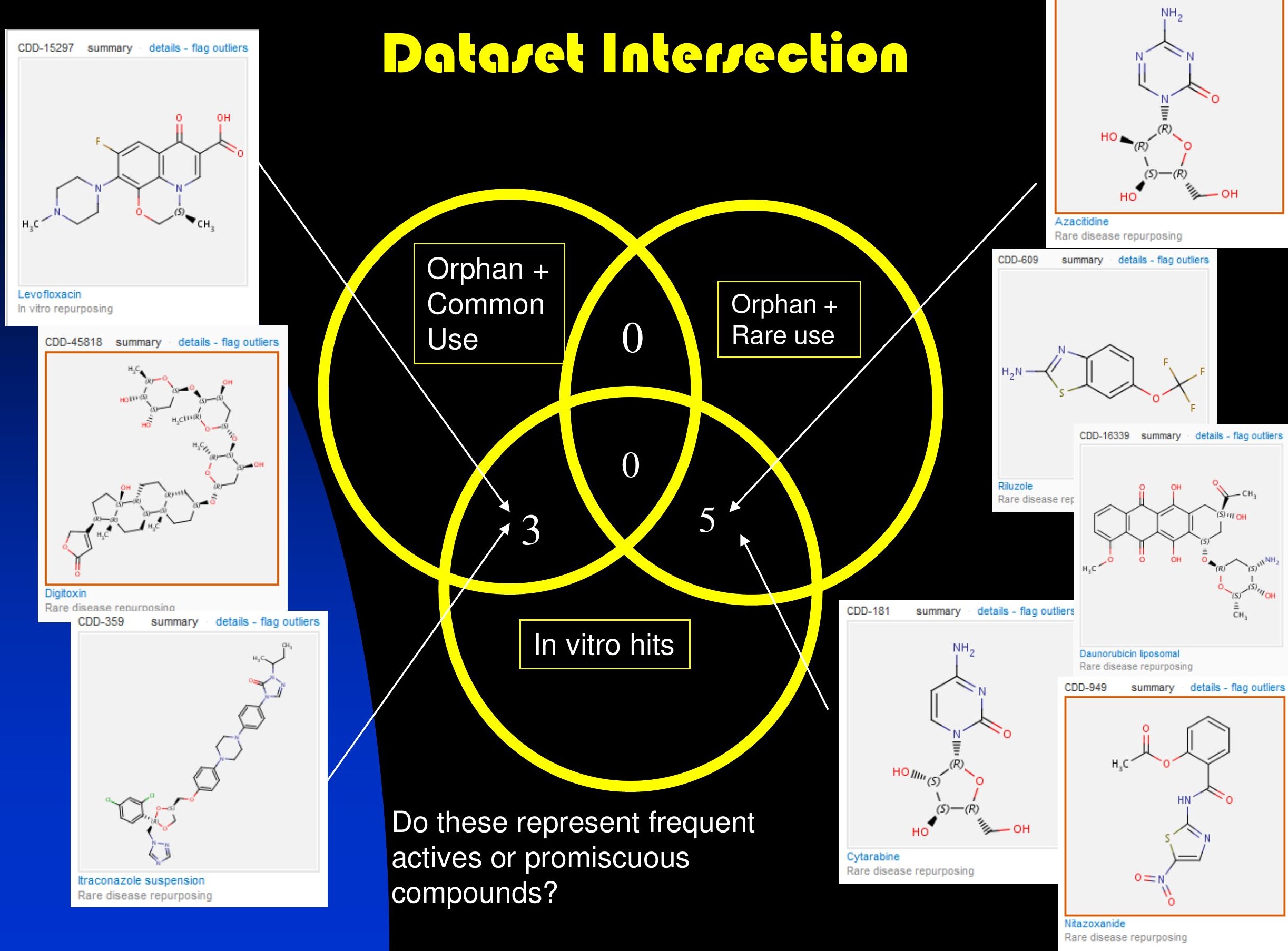




\section{finding Promireuous Old Prugs for hew Ures}

In vitro screening compounds repurposed -

Statistically more hydrophobic (log P) and higher MWT than orphandesignated products with at least one marketing approval for a common disease indication or one marketing approval for a rare disease from the FDA's rare disease research database.

Created multiple structure searchable databases in CDD

Data for repurposing in publications is increasing but who is tracking it?

Limited follow up of compounds from in vitro to in vivo..

Will any of these compounds from in vitro be approved?

Then the NPC browser was released early 2011 


\section{Data Errors in the APO Browsers Analysis of Steroids}

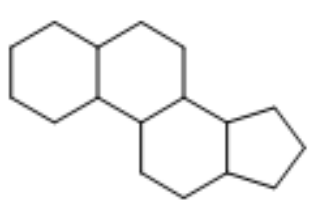

gonane

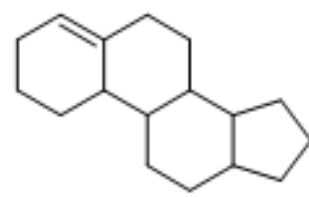

gon-4-ene

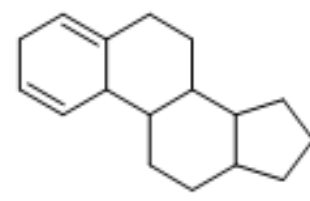

gona-1,4-diene

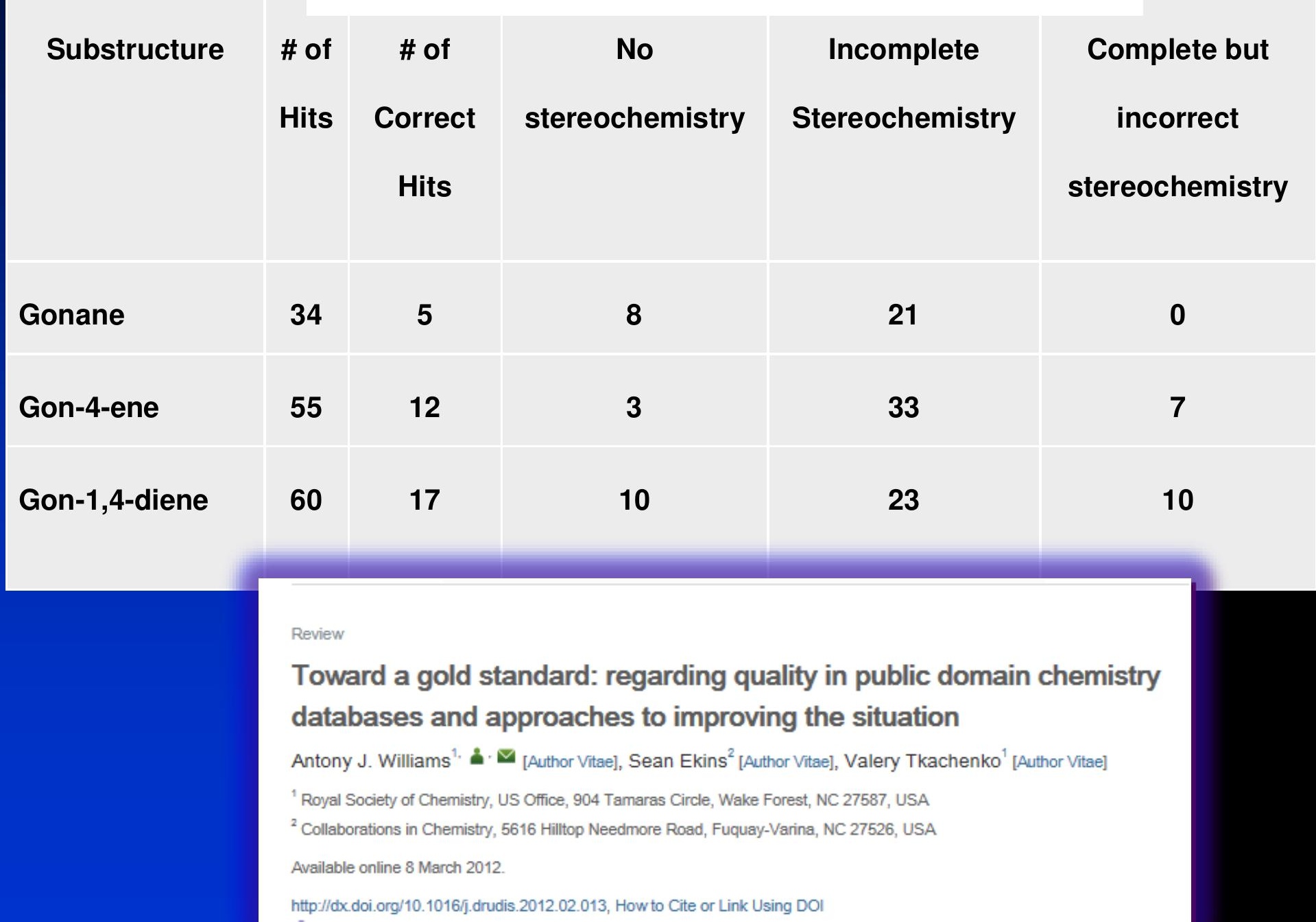




\section{Why drug strueture quality is importants}

More groups doing in silico repositioning

Target-based or ligand-based

Network and systems biology

They are all integrating or using sets of FDA drugs...if the structures are incorrect predictions will be too..

What is need is a definitive set of FDA approved drugs with correct structures and tools for in silico screening

Also linkage between in vitro data \& clinical data 


\section{Repurpore fPA drugs in silieo}

Key databases of structures and bioactivity data

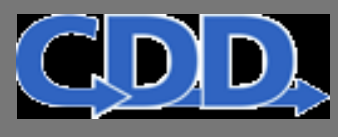

ChemSpider

Building community for chemists

\section{PubChem}

ChEMBL

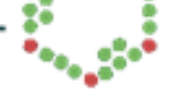

\section{DrugBank}

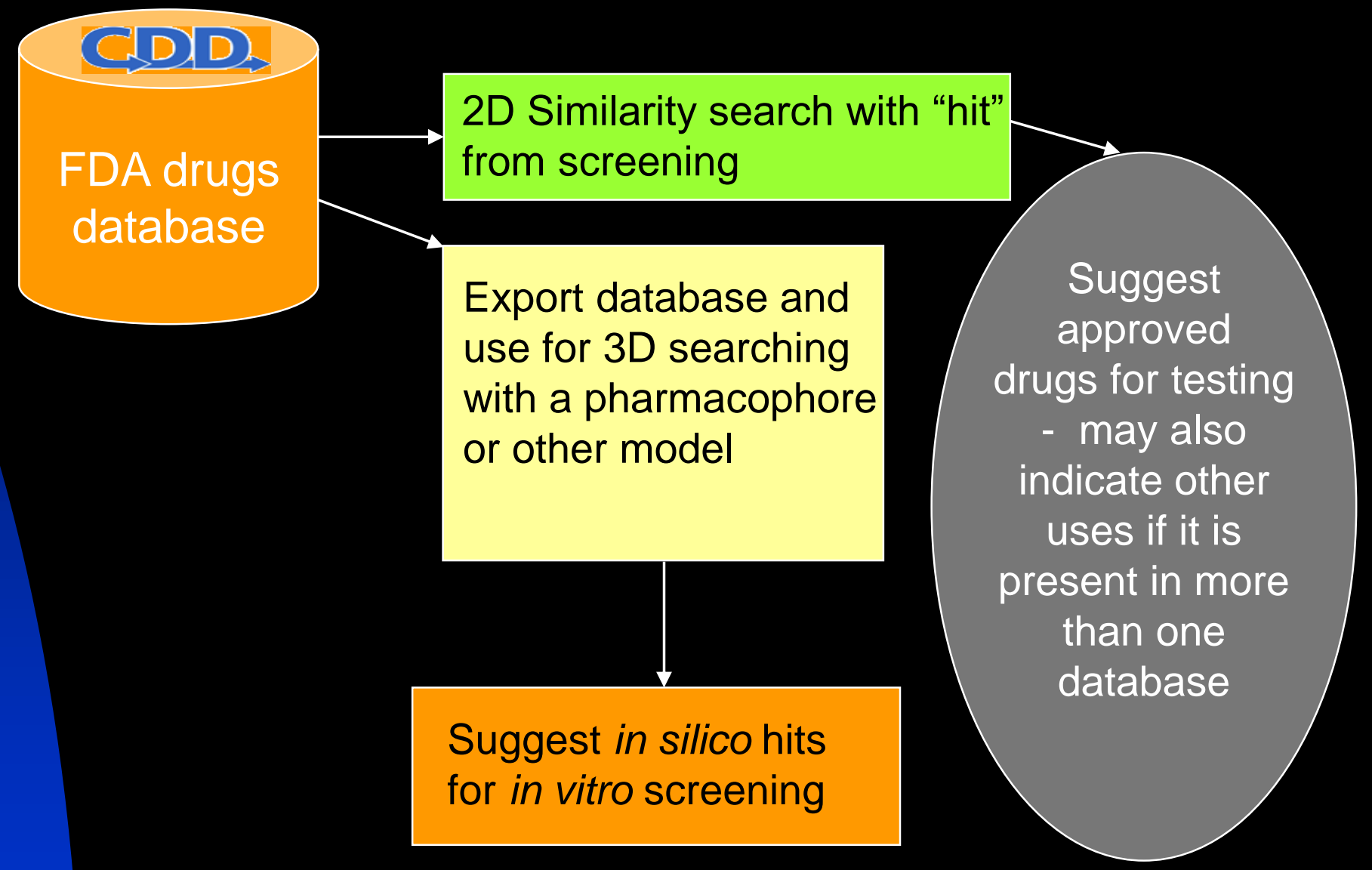

Ekins S, Williams AJ, Krasowski MD and Freundlich JS, Drug Disc Today, 16: 298-310, 2011 


\section{An erample for TB and mors}

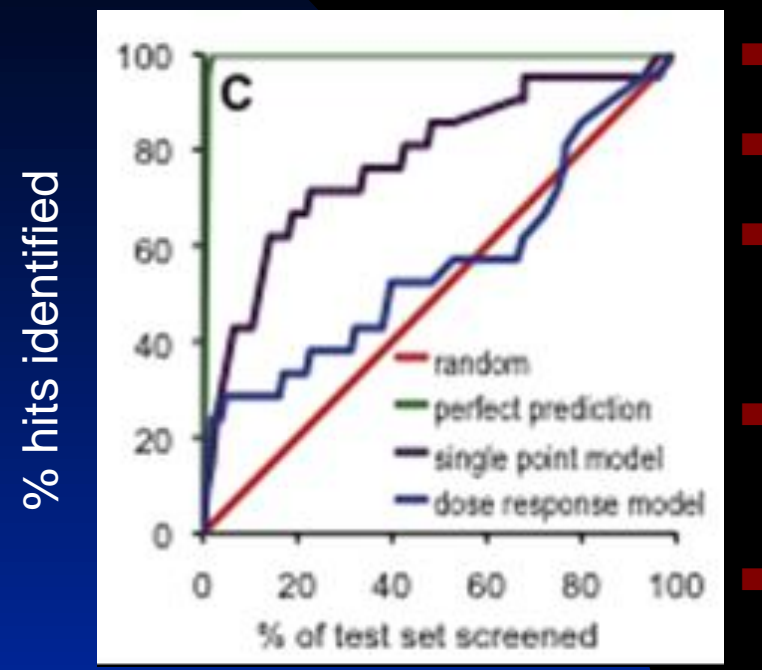

Bayesian models for TB whole cell data 200,000 single point

Over 2000 dose response

Used publication that identified compounds with whole cell activity FDA drugs 2108 molecules (21 actives)

Lougheed et al., Tuberculosis (2009) 89:364-70

Numerous examples of pharmacophores screening drugs and finding transporter inhibitors, PXR agonists, PXR antagonists etc..

Ekins et al., Mol Pharmacol, 74(3):662-72 , (2008)

Could use large datasets for other diseases, targets to build models search FDA drugs.... and repurpose

Ekins et al., Mol BioSyst, 6: 840-851, 2010 Ekins and Freundlich, Pharm Res, 28, 1859-1869, 2011 


\section{need to learn from neglected direare researeh}

\section{CDD. $=$ Sean Ekins, November 2010}

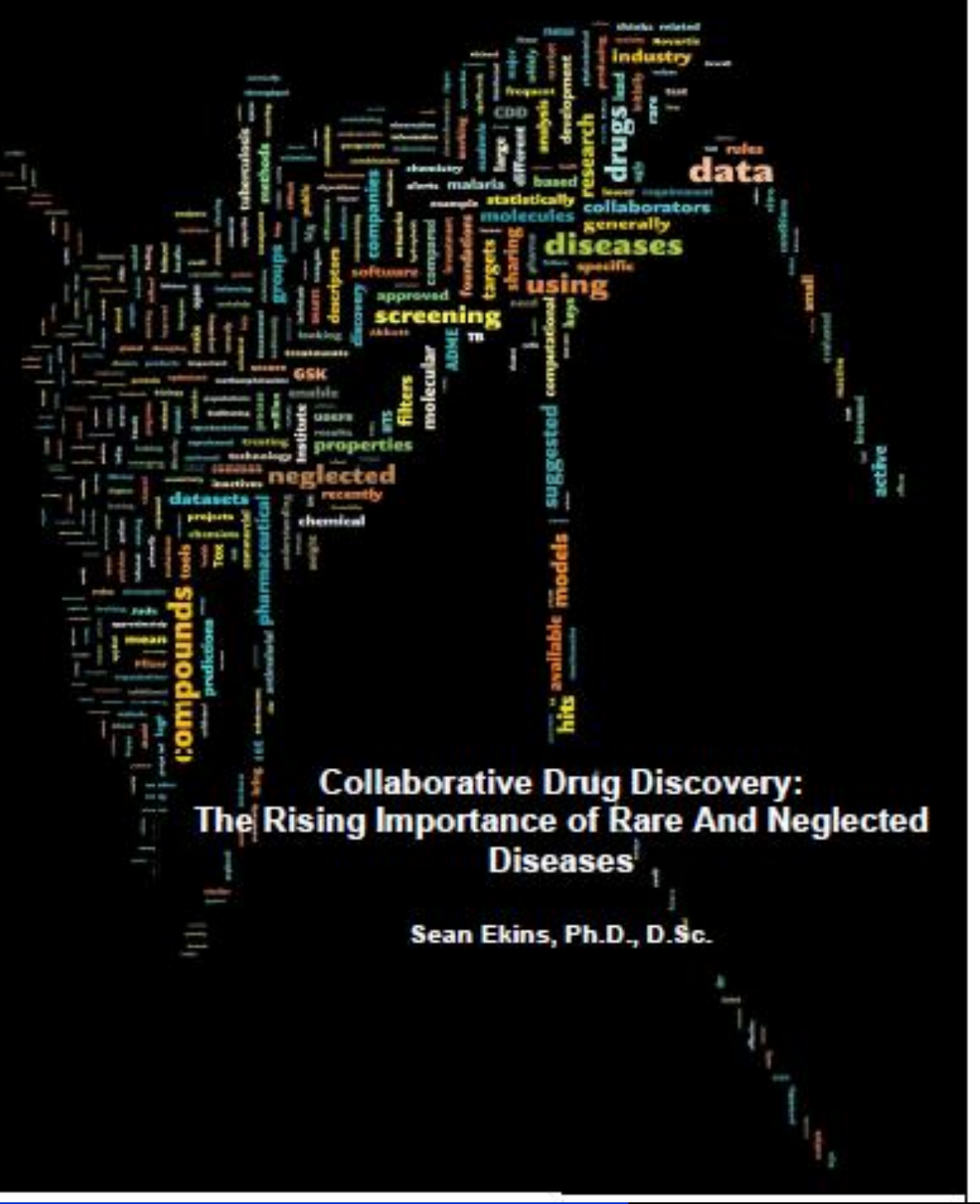

http://www.slideshare.net/ekinssean

\section{MedChemComm}

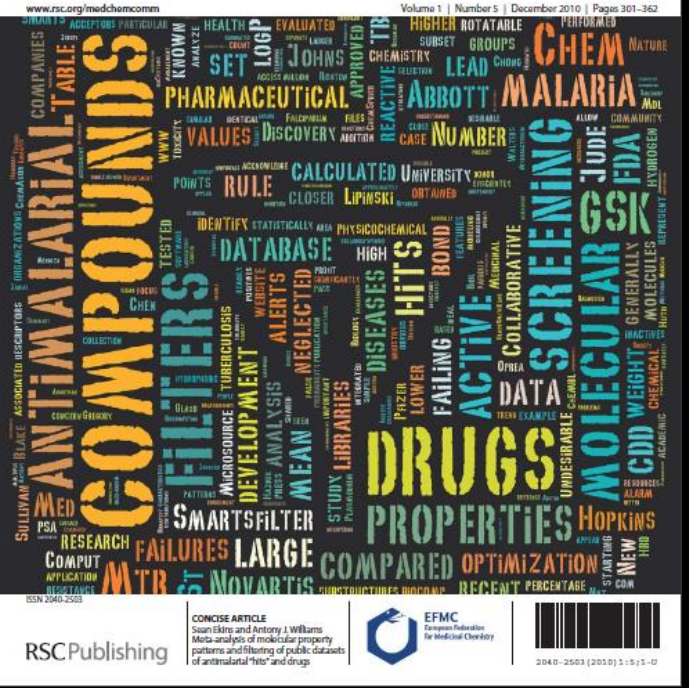

Do we really need to screen massive libraries of compounds as we have for TB and malaria?

And groups are screening compounds already screened by others!

Ekins $S$ and Williams AJ, MedChemComm, 1: 325-330, 2010. 


\section{Rare digearess Searehing for Potential Ohaperones for Sanfilippo Syndrome}
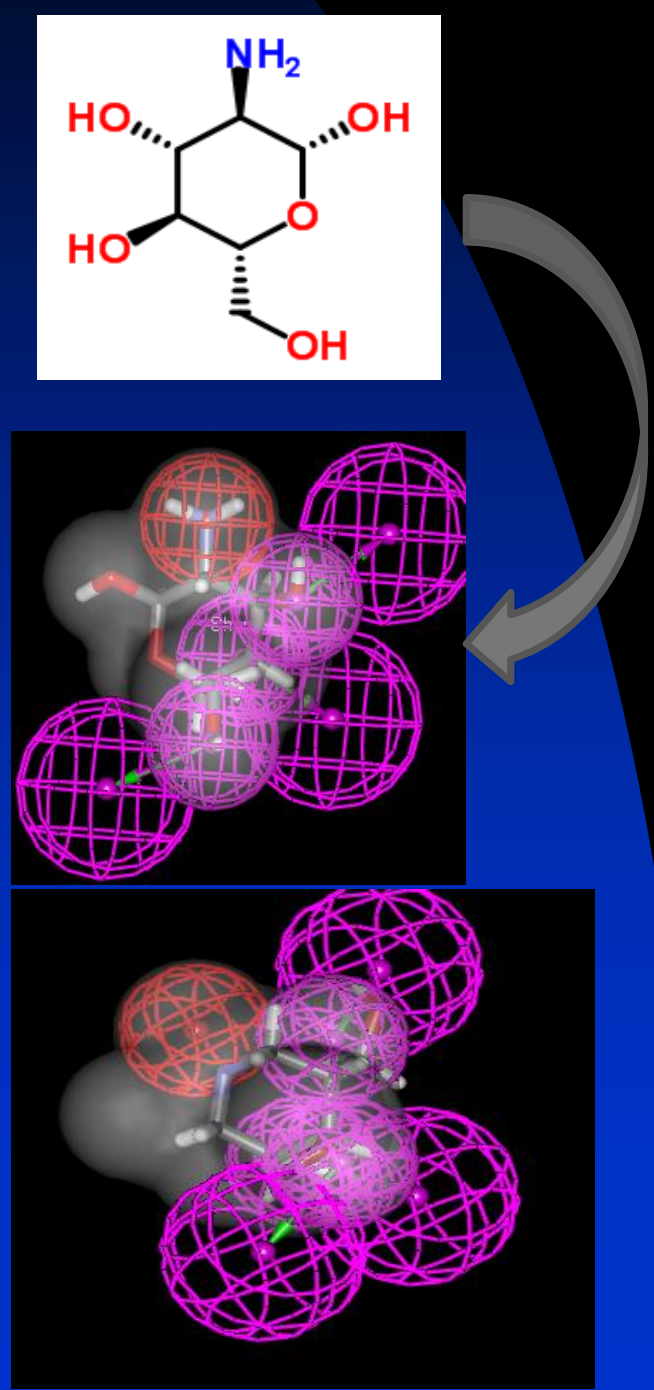

Pshezhetsky et al showed Glucosamine rescues HGSNAT mutants

Feldhammer et al., Hum Mutat. 2009 30:918-25

Glucosamine used to create a 3D common features pharmacophore using Discovery Studio.

The pharmacophore + ligand van der Waals shape was used to search multiple 3D databases

FDA drugs, natural products, orphan drugs, KEGG, CSF metabolome etc.

The pharmacophore consists of a positive ionizable (red) and 3 hydrogen bond donor groups (purple). Selected hits for experimental testing Collaboration ongoing!

e.g. Isofagomine maps pharmacophore 


\section{A path forwards for rare diseases uring old drugez}

We propose generalizable methods utilizing transcriptomic, system-wide chemical biology datasets combined with chemical informatics and, where possible, repurposing of FDA approved drugs for pre-clinical orphan disease therapies.

A generalizable pre-clinical research approach for orphan disease therapy Chandree L. Beaulieu et al., submitted 2012 


\section{Orowdroureing Projeet "Off the Shelf RE D"}
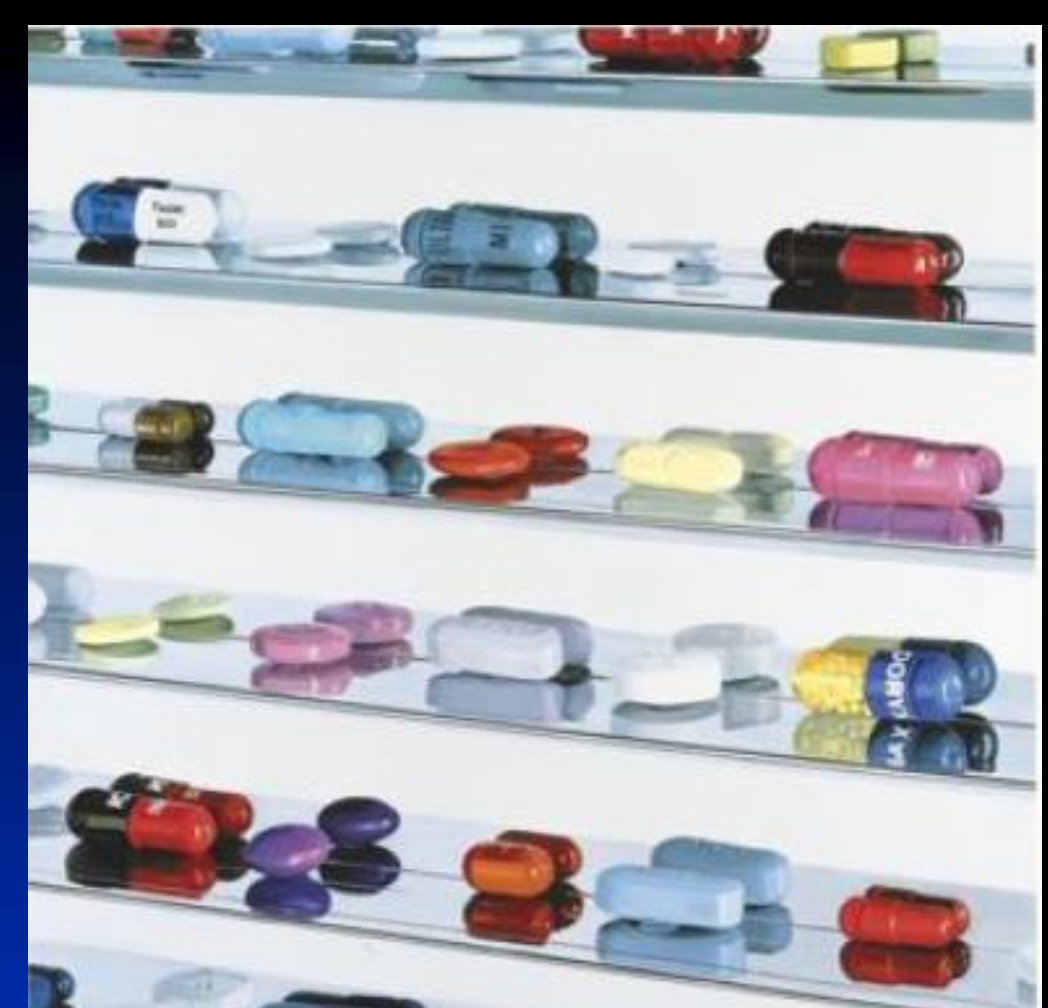

8

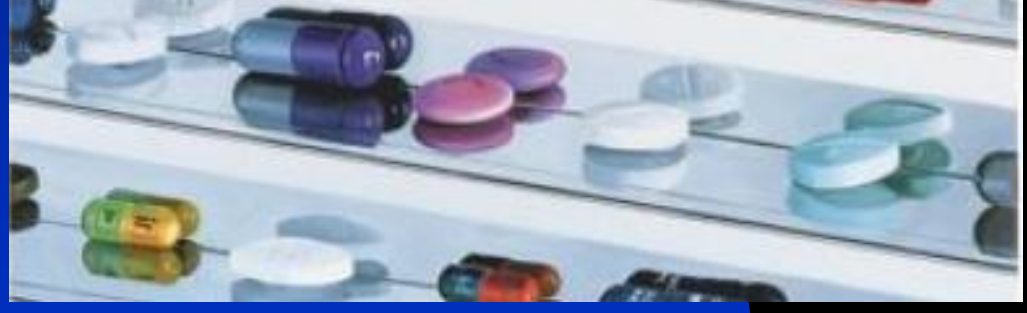

DAMIEN HIRST

B. 1965

PHARMACEUTICALS
How can we access more chemistry space?

All pharmas have assets on shelf that reached clinic "Off the Shelf R\&D"

Get the crowd to help in repurposing / repositioning these assets

How can software help?

- Create communities to test

- Provide informatics tools that are accessible to the crowd - enlarge user base

- Data storage on cloud - integration with public data

- Crowd becomes virtual pharma-CROs and the "customer" for enabling services 


\section{Finding Promireuous Old Prugs for hew Uses Update $2011-2012$}

Antivir Chem Chemother. 2012 Feb 28 doi: 10.3851/IMP2080. [Epub ahead of print]

Inhibition of Influenza A Virus Replication by Antagonism of a PI3KAKT-mTOR Pathway Member Identified by Gene Trap Insertional Mutagenesis.

Murray JL, McDonald NJ, Sheng J, Shaw MW, Hodge TW, Rubin DH, O'Brien WA, Smee DF.

【Invest Dermatol. 2011 Dec;131(12):2467-76. doi: 10.1038/jid.2011.300. Epub 2011 Sep 22.

Rapamycin suppresses self-renewal and vasculogenic potential of stem cells isolated from infantile hemangioma.

Greenberger S, Yuan S, Walsh LA, Boscolo E, Kang KT, Matthews B, Mulliken JB, Bischoff J.

Neuro Oncol. 2011 Sep;13(9):974-82. Epub 2011 Jul 15.

Antiparasitic mebendazole shows survival benefit in 2 preclinical models of glioblastoma multiforme.

Bai RY. Staedtke V. Aprhys CM Gallia GL. Riggins GJ everolimus

\section{5-fluorouracil}

Cancer Cell. 2011 Sep 13:20(3):384-99. doi: 10.1016j.ccr.2011.08.013.

An integrated in vitro and in vivo highthroughput screen identifies treatment leads for ependymoma.

Atkinson JM, Shelat AA, Carcaboso AM, Kranenburg TA, Amold LA, Boulos N, Wright K, Johnson RA, Poppleton $\mathrm{H}$, Mohankumar KM, Eéau C, Phoenix T, Gibson $\mathrm{P}$, Zhu L, Tong $\mathrm{Y}$,

$\underline{\text { Ed. }}$ R.

\section{ceftriaxone}

J Cell Physiol. 2011 Oct:226(10):2484-93. doi: 10.1002/jcp.22609.

Role of excitatory amino acid transporter-2 (EAAT2) and glutamate in neurodegeneration: opportunities for developing novel therapeutics.

Kim K, Lee SG, Kegelman TP, Su ZZ, Das SK, Dash R, Dassupta S, Barral PM, Hedvat M, Diaz , Reed JC, Stebbins IL, Pellecchia M, Sarkar D, Fisher PB

\section{Could In silico / in vitro repositioning find leads-drugs quicker?}




\section{Acknowledgments}

\section{Jill Wood}

Joel Freundlich (UMDNJ),

Matthew D. Krasowski (University of lowa)

Chris Lipinski

David Sullivan (Johns Hopkins)

Accelrys

CDD - Barry Bunin

Everyone that has shared data in CDD..

Email: ekinssean@yahoo.com

Slideshare: http://www.slideshare.net/ekinssean

Twitter: collabchem

Blog: http://www.collabchem.com/

Website: http://www.collaborations.com/CHEMISTRY.HTM

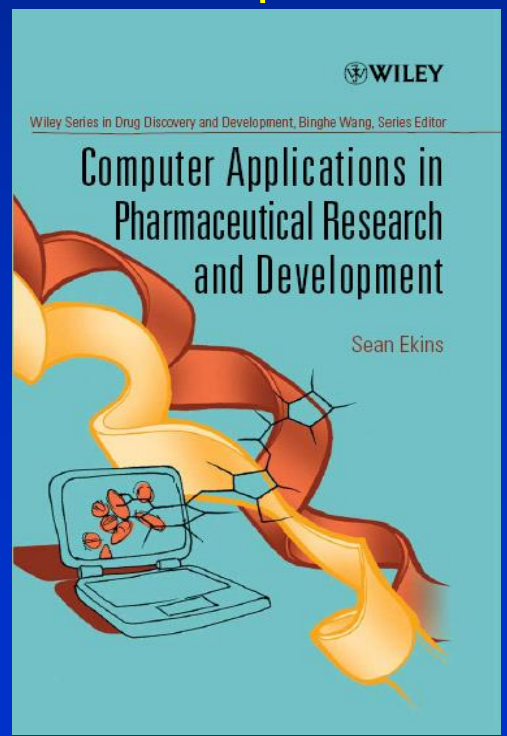

Drug Efficacy, Safety, and Biologics Discovery

Emerging Technologies and Tools

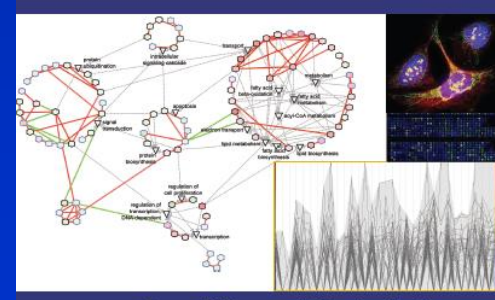

Edited by Sean Ekins and Jinghai J. XU

(8)WILEY
Computational Toxicology

Risk Assessment for Pharmaceutical

and Environmental Chemicals

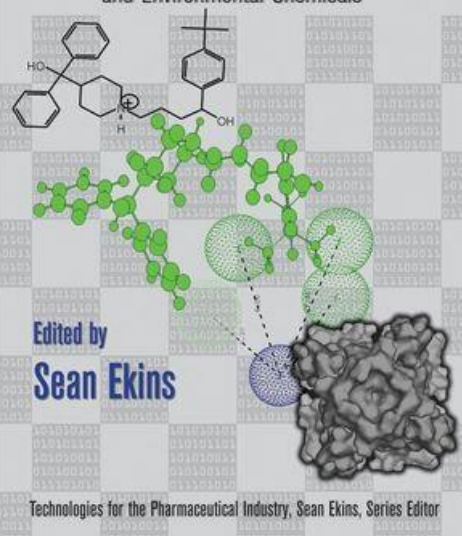

Collaborative Computational Technologies for Biomedical Research

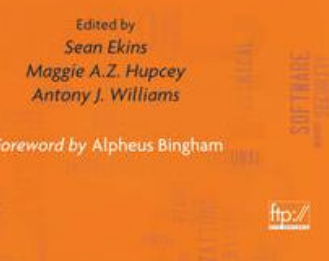

